\title{
Ethos discursivo e produção de sentidos: representações de infâncias nos anúncios de organizações bancárias
}

\author{
Pâmela Caroline STOCKER ${ }^{1}$
}

\begin{abstract}
Resumo:
Compreendendo a comunicação organizacional como produtora de sentidos e a publicidade como artefato cultural, este artigo tem como objetivo verificar as imagens de si ofertadas pelas organizações bancárias em seus anúncios,empregando representações de infância. O corpus constitui-se de três anúncios que circularam no mês de outubro de 1989, 1998 e 2003 na revista Veja. O referencial metodológico compreende elementos doethos discursivo, da semiose peirceana e da análise do discurso, desenvolvida por Verón (2004). Evidenciou-se nos anúncios-tipo denominados amor incondicional uma representação de infância clássica (obediente, meiga e ingênua) fundamental na constituição do ethosdiscursivo das organizações. É possível afirmar que o acionamento de representações infantis configura qualificada estratégia que colabora para a cristalização dos significados atribuídos à infância na sociedade e reforça opoder das organizações na constituição e compreensão dos fenômenos da cultura.

Palavras-chave:

Comunicação Organizacional. Representação de infância. Publicidade. Produção de sentidos. Ethos discursivo.

\section{Ethos discursive and production of meanings: childhoods representations through the advertisements of banking organizations}

\begin{abstract}
:
Understanding organizational communication as a producer of meanings and advertising as a cultural artifact, this article aims to verify the images of themselves offered by banking organizations in their advertisements, employing representations of childhood. The corpus consists of three advertisements that circulated in the month of October 1989, 1998 and 2003 in the magazine Veja. The methodological framework includes elements of the discursive ethos, Peircean semiosis and discourse analysis, developed by Verón (2004). In the type-ads called unconditional love, a classic (obedient, meek and naive) representation of childhood is fundamental to the constitution of the discursive ethos of organizations. It is possible to affirm that the activation of child representations constitutes a qualified strategy that contributes to the crystallization of the meanings attributed to childhood in society and reinforces the power of organizations in the constitution and understanding of the phenomena of culture.

Keywords:

Organizational communication. Childhood representation. Publicity. Production of meanings. Ethos discursive.

\section{Ethos discursivo y laproducción de significados: representaciones de lainfancia en lapublicidad de lasorganizaciones bancarias}

Resumen:

Mediante lacomprensión de lacomunicación organizacional como productora de significados y lapublicidad como unartefacto cultural, este artículo tiene como objetivo comprobarlasimágenesofrecidas por lasorganizaciones bancarias en sus anuncios que empleanrepresentaciones de lainfancia. El corpus se compone de tresanuncios que circulabanenoctubre de 1989, 1998 y 2003 enla revista Veja. El marco metodológico incluye elementos de ethos discursivo, de semiosis de Peirce y análisisdel discurso, desarrollado por Verón (2004). Se presentóenlosanunciosllamadosamor incondicional una

\footnotetext{
${ }^{1}$ Jornalista e doutora em Comunicação e Informação pela Universidade Federal do Rio Grande do Sul (UFRGS).E-mail: pamelastocker@gmail.com
} 
representaciónclásica de laniñez (obediente, amable yingenua) fundamental enlaconstitucióndelethos discursivo de lasorganizaciones. Se puede afirmar que lasrepresentaciones de losniños se utilizan como estrategiacualificada, lo que contribuye a lacristalización de los significados atribuidos a lainfanciaenla sociedade y fortalece el poder de lasorganizacionesenlaconstitución y lacomprensión de los fenómenos culturales.

Palabras clave:

Comunicación organizacional. La representación de laniñez. Publicidad. La producción de significados. Ethos discursivo.

\section{Introdução}

Compreender a comunicação organizacional como construtora e propositora de sentidos é também observar os diferentes modos de produção e circulação de discursos na sociedade. Nessa conformação, os anúncios das organizações fazem mais do que apenas publicizar ações, produtos e serviços. Como materializações discursivas, têm potência para influenciar na configuração da cultura, naturalizando e (re)afirmando modos de ser e estar no mundo.

Atentas a estratégias para que possam conquistar a simpatia - tendência ao mesmo, conforme Foucault (1999) - dos públicos, gerando identificações, diversas organizações optam por associar discursivamente a noção de infância a sua marca ou aos seus produtos e serviços. Dentre elas, os bancos aparecem como as organizações que mais empregam a noção de infância em seus anúncios (ANDRADE, 2011).

Dado esse contexto, o interesse deste artigo $^{2}$ está voltado para a comunicação organizacional dos bancos que empregam representações de infância em sua publicidade. Observa-se o fenômeno na revista Veja, mais precisamente, em três anúncios de bancos veiculados em suas páginas nos meses de outubro de 1989, 1998 e 2003. O objetivo do estudo, fruto da dissertação de mestrado intitulada Comunicação Organizacional e ethos discursivo: representações de infância em anúncios de bancos veiculados na revista Veja (1968-2011), é verificar as representações de infância acionadas pelos anúncios-tipo classificados no grupo ${ }^{3}$ Amor incondicional, investigar o ethos discursivo ofertado por essas organizações e problematizar os efeitos desses discursos organizacionais no processo de produção e legitimação de sentidos sobre a infância na sociedade.

\footnotetext{
${ }^{2}$ Texto elaborado com dados da pesquisa de mestradodesenvolvida pela autora. Destaca-se que o corpus total do estudocompreende 59 anúncios, publicados entre 1968-2011, porém, neste artigo o recorte compreende apenas os anúncios-tipo denominados Amor incondicional publicados nesse recorte temporal.

${ }^{3}$ Cinco grupos de anúncios-tipo foram identificados no estudo realizado para a dissertação, a partir das representações de infânciaacionadas pelas organizações: Amor incondicional, Despesas e gastos, Vetor para o consumo, Desmitificação do novo e Futuro da nação. Como jádito, neste artigo o foco compreende apenas os anúncios-tipo pertencentesao grupo Amor incondicional.
} 
Comunicação organizacional: ofertas de si na publicidade

Pensar a comunicação e a comunicação organizacional implica considerar uma série de compreensões distintas sobre o fenômeno. Dentre a diversidade de reflexões a respeito, importa delimitar a compreensão assumida neste texto, que considera a comunicação como um processo caracterizado principalmente por sua inconstância, imprevisibilidade e possibilidades. Nessa direção, julga-se que as relações comunicacionais estão sempre envolvidas com a interpretação e disputa de significação.

A partir do "paradigma da complexidade", de Edgar Morin, Baldissera (2009, p. 116) propõe compreender a Comunicação Organizacional como "processo de construção e disputa de sentidos no âmbito das relações organizacionais". Assumir esse paradigma significa pensar a Comunicação Organizacional além dos processos formais de comunicação, aguçando o olhar para as tensões, disputas e perturbações, ou seja, a permanente desorganização/ (re)organização presentes nos processos comunicacionais (BALDISSERA, 2009).

Considerando a complexidade das organizações, percebe-se que os fragmentos de identidade (partes) escolhidos para serem comunicados via publicidade são elevados à categoria de todo. São apresentados como sendo a própria organização e a própria identidade, e não vistos apenas como fragmentos dela. Mais do que prática social, os discursos dos bancos são processos sociais de produção de sentido, resultantes de processos histórico-sociais, produzidos em condições específicas. Assim como outros processos formais de comunicação organizacional, a publicidade constitui-se em importante e fundamental dinamizadora do discurso organizacional na medida em que potencializa sua visibilidade e abrangência.

Considerando as organizações como sujeitos em interação (BALDISSERA; SILVA, 2011), é possível afirmar que, personificadas dessa forma, as organizações possam editar a si mesmas (por vezes de forma estratégica) antes de oferecerem-se aos públicos. A competitividade do mercado, a disputa por visibilidade positiva, posicionamento e permanência, imagem-conceito, capital e poder simbólicos configuram-se em permanente necessidade de legitimação das organizações. Nesse sentido, a comunicação e, mais precisamente, a publicidade, atua como elemento de (re)afirmação da identidade organizacional. É por meio dos seus discursos que a organização procura prover uma imagem de si, ou uma autoimagem, atentando para o que Maingueneau (2008a) chama de ethos discursivo.

A partir da concepção aristotélica, Maingueneau compreende o ethos discursivo 
como o mecanismo que possibilita que o orador se torne digno de fé e, em última instância, está relacionado à construção de uma identidade desse orador, com a utilização de estratégias de fala que sejam capazes de agradar à audiência: "Consiste em causar boa impressão mediante a forma como se constrói o discurso, em dar uma imagem de si capaz de convencer o auditório, ganhando sua confiança" (MAINGUENEAU, 2008b, p. 56).

Com efeito, vê-se que o ethos não mobiliza somente o discurso em si, mas um conjunto de caracteres que envolvem o ato de enunciar. No caso da publicidade, a escolha dos signos verbais, das imagens e cenas que ilustram o anúncio ou a forma como o produto ou serviço é apresentado ao público intenta, primeiramente, dizer desse produto ou serviço e produzir uma imagem positiva. Porém, ao mesmo tempo, a escolha desses elementos e a forma como são apresentados implicam na atribuição de um caráter e uma corporalidade às organizações bancárias por parte dos públicos. A partir do anúncio publicitário (enunciação), cria-se certa representação da organização bancária (enunciador responsável pelo discurso).

Não se trata de afirmações que a organização pode fazer a respeito de si mesma no conteúdo do seu discurso - o que certamente faria com que perdesse credibilidade e simpatia - mas a aparência que a escolha das palavras, das imagens e dos argumentos presentes nos anúncios lhe confere. O ethos é pensado por Maingueneau como uma noção discursiva, que se constrói por meio do discurso, não como uma imagem do locutor exterior a sua fala.

Importa relembrar que, de acordo com Baldissera e Silva (2011), o discurso organizacional tende a observar as representações, valores e crenças dos seus públicos para, de alguma forma, traduzi-los em enunciados. Na mesma direção, “os públicos, racionalmente ou não, inclinam-se a valorar positivamente as organizações que, de algum modo, reproduzem e devolvem seus próprios valores" (BALDISSERA; SILVA, 2011, p. 7), isto é, espelham, de alguma forma e em algum nível, os valores dos públicos.

Dessa forma, pode-se afirmar que a questão do ethos está ligada à construção da identidade das organizações. A forma como a organização se posiciona discursivamente tende a obedecer a algumas regras e a dizer de como ela se vê, ou de como quer ser vista (BALDISSERA; SILVA, 2011). Considerando que o anúncio deve conquistar um público que pode ignorá-lo ou recusá-lo, “a noção de ethospermite refletir sobre o 
processo mais geral da adesão dos sujeitos a determinado posicionamento" (MAINGUENEAU, 2008b, p. 64). Nessa perspectiva, a maneira de dizer é também a mensagem. São as "ideias" que suscitam a adesão do público "por meio de uma maneira de dizer que é também uma maneira de ser" (MAINGUENEAU, 2008a, p. 72).

Assim, a infância pensada como âncora para a noção de ethos discursivo nos anúncios ratifica a compreensão de Maingueneau sobre o discurso publicitário. Para o autor, a publicidade mantém, por natureza, uma ligação privilegiada com o ethos, pois "busca efetivamente persuadir ao associar os produtos que promove a um corpo em movimento, a uma maneira de habitar o mundo. Em sua própria enunciação, a publicidade pode, apoiando-se em estereótipos validados, 'encarnar' o que prescreve" (MAINGUENEAU, 2008a, p. 19, grifo do autor). No espaço privilegiado da publicidade, que está "entre as principais produtoras de sistemas simbólicos do nosso tempo" (ROCHA, 2006, p. 12), o acionamento das representações de infância pelas organizações bancárias e as imagens de si ofertadas estrategicamente a partir do emprego dessas representações reiteram a comunicação organizacional como importante produtora de sentidos na sociedade.

\section{Infância, produção de sentido e representações}

Embora as crianças sempre tenham existido, nem sempre houve a infância no sentido que se compreende hoje, como categoria social de estatuto próprio. Postman (1999) e Ariès (1988) trabalham com a noção de infância não como necessidade biológica e, sim, como artefato social que muda de acordo com o tempo e com as diferentes culturas. Os autores argumentam que na Idade Média, por exemplo, não existia o sentimento de infância tal qual se conhece hoje, e as crianças eram consideradas como meros seres biológicos, sem estatuto social e nem autonomia existencial.

Os significados atribuídos à infância na sociedade contemporânea continuam sendo vistos como universais e atemporais. Para o senso comum, a infância representa um momento privilegiado, em que se manifesta da forma mais original a pureza, a inocência e as melhores promessas do gênero humano (BUJES, 2003). Segundo Bujes (2003), isso acontece porque a infância costuma ser pensada de um modo idealista, dentro da perspectiva moderna de "invenção" ou "descoberta" da infância:

[...] a idéia de que a infância foi descoberta pressupõe que certas características universais das crianças e de um modo de viver a infância só vieram a ser percebidas em determinado momento histórico, num contexto de 
reflexão filosófica e atividade científica. As crianças possuiriam certas características essenciais - que sempre estiveram nelas presentes - que serviriam de fundamento para os processos naturais (e também universais) que caracterizariam sua infância. (BUJES, 2003, p. 6).

Isso acontece porque as crianças têm sido produzidas por vários discursos que acabam construindo uma posição de sujeito ideal, um sujeito universal, sem cor, sem sexo, sem filiação, sem amarras temporais ou espaciais. Dentre as muitas vozes que regulam a infância, é possível apontar os discursos médico, biológico, antropológico, psicológico e pedagógico, que levam à naturalização de determinados conceitos relativos às crianças.

Importa notar que, por suas características, a infância é vista e tratada nas relações cotidianas como campo isento de poder. Porém, Bujes (2003, p. 9) alerta para a maneira como determinados regimes de verdade operam naquilo que chama de "governamento da infância". A partir de uma visão foucaultiana, a autora compreende essas "verdades" acerca da infância como um empreendimento histórico, como mecanismo centralmente envolvido com o exercício do poder.

Nesse sentido, a noção de infância foi e continua sendo fabricada pelos discursos institucionais, pelas formulações científicas, pelos meios de comunicação de massa, pela publicidade, entre outros. Bujes (2003) ressalta que uma série de discursos ritualizados têm sido aceitos acriticamente graças a esse apagamento das relações entre infância e poder. Nessa perspectiva, ressalta que "todas as formulações sobre crianças e infância que, por longo tempo, vêm sendo tomadas como inquestionáveis, não pertencem ao domínio do sagrado, são coisas deste mundo, efeitos de jogos de poder e de vontade de saber" (BUJES, 2003, p. 9).

Kohan (2003) relembra que, para Foucault (1999), o poder não é algo que se toma, algo que se tem ou se conquista, mas algo que se exerce. Isso não significa que exista o poder de um lado e os indivíduos de outro, mas, sim, indivíduos exercendo poderes na chamada arte do governo. Como enfatiza Bujes (2003), esse poder não deve ser pensado em sua face repressiva, numa concepção puramente jurídica, como uma força que proíbe, que diz não. Refere-se ao poder que seduz, acumplicia, não se mostra, com capacidade de produzir prazeres, saberes, discursos. Para a autora, deve-se abandonar a hipótese repressiva, a noção negativa do poder, para vê-lo se exercendo em todas as práticas, sustentando-se, inclusive, em verdades amplamente aceitas e festejadas. Portanto, devem ser objetos da atenção não apenas os modos de operar do 
poder, mas, igualmente, as verdades que sustentam o seu exercício.

Nessa ótica, governo não quer dizer aparato estatal, mas o modo como se dirige, em qualquer âmbito, a conduta dos indivíduos. Evocando o conceito de governamento, fundamental para Foucault, a autora define governar como estruturar o possível campo de ação próprio ou alheio. Para Bujes (2003), o exercício de poder, então, é o modo como certas ações estruturam o campo de outras possíveis ações.

Ainda que o campo das estratégias para governar os seres humanos interesse fundamentalmente ao Estado, o governamento se realiza a partir de múltiplos interesses, em muitos lugares distribuídos pela sociedade. Trata-se de um governo distribuído microscopicamente pelo tecido social, que busca atingir o máximo de resultados com mínima aplicação do poder (BUJES, 2008, p. 107). É a partir da normatividade - função principal do poder disciplinar - que se distingue "o permitido e o proibido, o correto e o incorreto, o são e o insano" (KOHAN, 2003, p. 73).

Existem assim inúmeras possibilidades de esquadrinhar os modos como o poder se exerce sobre a criança. São as verdades que estão implicadas nessas estratégias que funcionam como meios para manter e fazer funcionar os dispositivos de governamento:

[...] com o advento da Modernidade as crianças, como parte da população, passaram a ser medidas, calculadas, categorizadas, descritas, ordenadas e organizadas não só do ponto de vista estatístico, mas também pela produção crescente de conhecimento sobre elas e sobre os fenômenos de sua vida, o que é revelador de um fato: elas se tornaram, assim, alvo de determinadas instituições e objetos de saber. (BUJES, 2003, p. 10).

Outras iniciativas amplamente disseminadas e de grande apelo estiveram/estão centralmente comprometidas com a administração da infância e pode-se dizer que a mídia é uma delas. Para Bujes (2003), basta encarar determinadas verdades relacionadas à noção de infância com estranhamento, para que a concepção de criança legada pela Modernidade seja colocada em xeque. É possível apontar a inexistência de uma infância referência, o que torna problemáticas as formas de conceber as coisas da realidade e coloca em questão "os regimes de verdade estabelecidos, os raciocínios amplamente aceitos, os modos de falar corriqueiros, tornando a linguagem um alvo de problematização" (BUJES, 2003, p. 5).

Para a autora (2003), os regimes de verdade operam realizando um estrito controle sobre os discursos e levando a uma naturalização dos conceitos. As ideias existentes sobre criança e infância não correspondem a uma verdade última que as caracterizaria; as palavras usadas para descrevê-las ou as imagens utilizadas para 
representá-las não passam de modos históricos de referir-se a elas. A ideia de que existe um conhecimento objetivo e até mesmo científico acerca da infância é um efeito dos discursos que se constituíram/constituem sobre ela, produto das relações entre verdade e poder.

Esse quadro de saberes circunscreve um entendimento, que é tomado como a forma adequada, correta, precisa, normal e natural de significar a infância, não apenas descrevendo-a, mas contribuindo para desencadear estratégias que visam a governá-la. Nessa perspectiva, pode-se dizer que a noção de infância continua sendo (re)criada e (re)definida nas sociedades contemporâneas. Conforme Buckingham (2007, p. 8), "a infância não é absoluta, nem universal, e sim relativa e diversificada. A ideia de infância é uma construção social, que assume diferentes formas em diferentes contextos históricos, sociais e culturais". Como construção cultural, a noção de infância está diretamente ligada à produção de sentidos e à representação.

Nessa conformação, entende-se, em consonância com Hall (1997), representação como parte essencial do processo pelo qual o significado é produzido e intercambiado entre os membros de uma cultura. É o uso que se faz das coisas, e o que se diz, pensa e sente sobre elas que determina seu significado. As formas empregadas para representar - palavras usadas, histórias contadas, imagens produzidas, emoções associadas e valores atribuídos - produzem significação, pois acionam a estrutura de interpretação dos indivíduos. A significação também é atribuída pela forma como as coisas são usadas ou integradas nas práticas do cotidiano.

Representações de infância e imagens de si nos discursos das organizações bancárias

Após a coleta e organização/tabulação dos dados referentes aos anúncios de organizações bancárias publicados na revista Veja, realizou-se o levantamento quantitativo do material. Dos 767 anúnciosencontrados no período 1968-2011, 59 empregaramrepresentações de infância. Esses 59 anúncios foram organizados, primeiramente, por década e, posteriormente, por tipo, sendo agrupados de acordo com a representação de infância acionada. Essa categorização foi inspirada no trabalho de Verón (2004) acerca dos discursos da imprensa. Segundo o autor, o corpus deve ser constituído por grupos de textos. Cada um desses grupos deve ser homogêneo do ponto de vista das condições extratextuais. No caso deste estudo, criaram-se grupos 
homogêneos de anúncios publicados em um mesmo período, sendo subdivididos por década. Neste artigo, o interesse está no grupo de anúncios-tipo denominado Amor incondicional.

O referido grupo contabilizou 16 anúncios entre 1968-2011. Sua principal característica consiste no acionamento de uma representação de infância clássica (obediente, meiga e ingênua), em geral empregada para relembrar ao adulto sua responsabilidade afetiva e mobilizar a culpa (compromisso de dedicar mais tempo para a convivência e interação com os filhos numa rotina cada vez mais atribulada). A ênfase dos anúncios desse grupo está relacionada à segurança e tranquilidade - onde a criança aparece brincando ou em momentos de interação com os pais, por exemplo - e à necessidade de fazer algo que garanta o futuro da criança como forma de demonstrar amor. Ao longo da análise, o grupo aparece de forma significativa entre 1980-1990 (quatro anúncios), mantém-se de forma menos expressiva entre 1991-2000 (apenas um anúncio) e, finalmente, retorna com força total (11 anúncios) no último período do estudo (2001-2011).

Os anúncios-tipo selecionados para a análise como representantes do grupo (Figuras 1, 2 e 3) foram escolhidos observando-se aquilo que Verón denominou "desvio zero" (2004, p. 68), ou seja, a equivalência dos anúncios dentro do agrupamento a que pertencem. O corpus advém dos grupos de anúncios-tipo identificados ao longo dos anos, tendo sido escolhido apenas um anúncio como representante de cada grupo, por julgar-se, desse modo, estar contemplando aquilo que circulou em cada década sob o prisma do tipo.

Figura 1 - Anúncio do Banco Real

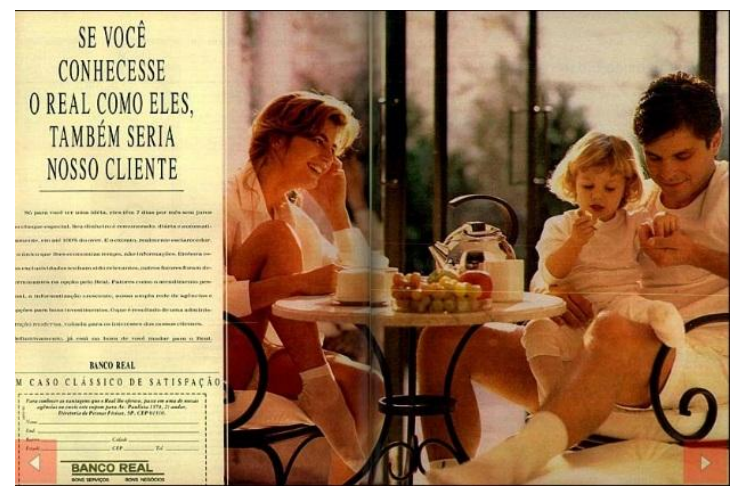

Fonte: Revista Veja, ed. 1099, 04 out.1989, p. 104-105. 
Figura 2 - Anúncio do Banco Itaú

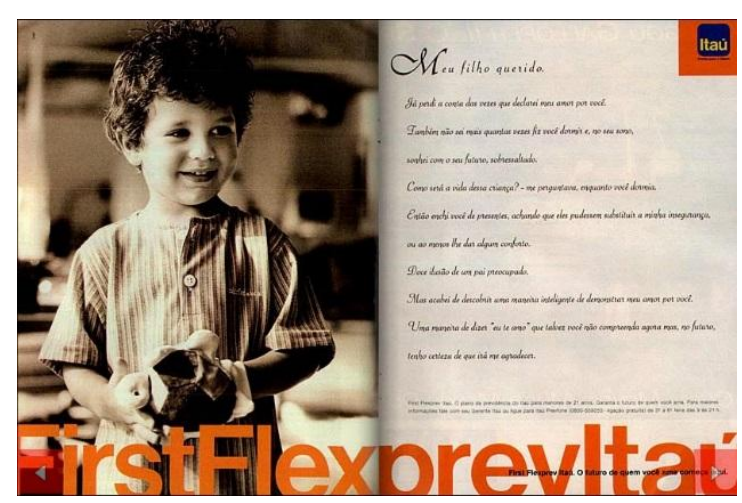

Fonte: Revista Veja, ed. 1568, 14 out. 1998, p. 72-73.

Figura 3 - Anúncio do Banco Itaú

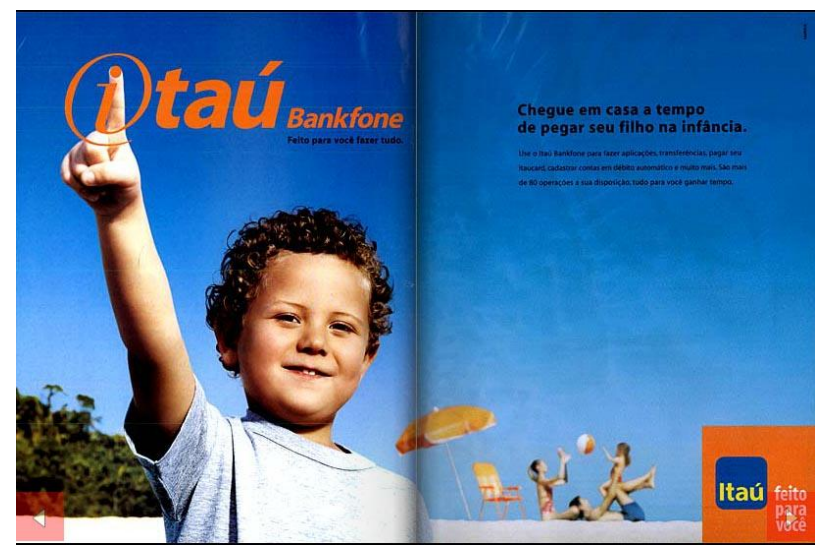

Fonte: Revista Veja, ed. 1822, 01 out. 2003, p. 2-3.

Para explorar o funcionamento do discurso publicitário das organizações, dois passos fundamentais, elencados por Verón (1980), foram norteadores das análises: a) o descritivo, em que se demarcou e descreveu as operações discursivas a partir das superfícies significantes. Nesse processo, as imagens, ilustrações e/ou textos dos anúncios foram submetidos a uma primeira leitura descritiva; b) o explicativo, em que se procurou demarcar as estratégias discursivas presentes nos anúncios no que concerne ao enunciado e à enunciação, além da identificação do ethosdiscursivo.

Nessa seção também foram identificadas pistas ou marcas que remetem ao ideológico e ao poder como dimensões fundamentais na análise do funcionamento da sociedade. Feito isso, foram apontadas as representações de infância acionadas pelo anúncio. Neste artigo, devido a questão do espaço, as análises serão apresentadas de 
forma sintética, priorizando os principais resultados encontrados nos anúncios do Banco Real (Figura 1), Banco Itaú (Figura 2 e 3), que serão explorados a seguir:

Banco Real: "Se você conhecesse o Real como eles, também seria nosso cliente"

A leitura visual do anúncio do Banco Real veiculado em 1989 (Figura 1) permite descrever um casal e uma criança vestidos de branco, sentados à mesa do café da manhã. $\mathrm{O}$ texto verbal do anúncio enumera vantagens exclusivas do cliente Real e procura convencer o leitor a tornar-se cliente. A fotografia da família sorridente em um momento de interação no café na manhã transmite a sensação de tranquilidade e associa essa condição àqueles que conhecem as vantagens de ser cliente Real.

Percebe-se o posicionamento de solidez e confiabilidade que o banco procura apresentar em contrapartida ao período conturbado que vivia a economia do país. Em 1989 entrava em vigor o Plano Verão ${ }^{4}$, congelando preços e salários e gerando desajustes e perdas na caderneta de poupança (FAUSTO, 2011). No texto verbal, o banco oferece serviços como cheque especial com sete dias por mês sem juros e opções para investimentos, ofertando opções para o cliente fugir das consequências do novo plano econômico.

O ethos discursivo ofertado pelo banco remete a uma organização segura em relação aos serviços que oferece e eficiente na execução do seu papel, garantindo tranquilidade para seu cliente. A representação de infância clássica (obediente, meiga e ingênua) aparece para completar a ideia de família nuclear e relembrar o adulto sobre sua responsabilidade afetiva em relação à família.

A estratégia adotada pelo banco baseia-se em demonstrar que momentos de interação e relaxamento junto aos filhos são possíveis no dia a dia quando se é cliente de um banco sério como o Real. Ao mesmo tempo em que a representação de infância mobiliza a culpa do adulto, o banco apresenta-se como a solução para o problema daqueles que avaliam ser necessário dedicar mais tempo e atenção aos filhos. Ao proporcionar um serviço de qualidade que resultará em tranquilidade, possibilita ao cliente esquecer as preocupações e aproveitar o tempo livre com a família.

\section{FirstflexprevItaú: "O futuro de quem você ama começa aqui"}

\footnotetext{
${ }^{4}$ Plano econômicolançado pelo governo do presidente José Sarney (1985-1990) na tentativa de controlar a inflação.
} 
A fotografia sépia de um menino vestindo pijamas e segurando um bichinho de pelúcia veiculada pelo banco Itaú em 1998 (Figura 2) apresenta o serviço de previdência privada de forma bastante sutil. O texto verbal simula as palavras de um pai preocupado com o futuro do filho. Por meio de uma carta endereçada à criança, ele garante ter encontrado "uma forma inteligente" de demonstrar o seu amor. Dessa forma, o texto publicitário procura convencer o leitor que o plano de previdência que oferece é a melhor forma de garantir o futuro de quem se ama.

Após a fase difícil enfrentada na economia nesse período, com um longo período de alta da inflação e instabilidade (FAUSTO, 2011), o banco aproveita-se do equilíbrio estabelecido no final da década para relembrar os tempos turbulentos, demonstrando a necessidade de garantir aos filhos um futuro tranquilo. A imagem de si (ethos) que a organização procura apresentar fica subentendida, juntamente com a ideia de que pretende ajudar sem pedir nada em troca (já que mais detalhes referentes ao serviço de plano de previdência não são mencionados). Dessa forma, o banco provoca a identificação ao fazer com que o público tenda a perceber o serviço com simpatia. A fotografia da criança em primeiro plano em junção ao texto verbal em destaque denota apelo afetivo (pureza, inocência), um lembrete àqueles que também possuem filhos e sentem-se em dívida com eles. A representação de infância acionada relembra a responsabilidade do adulto e mobiliza a culpa e a necessidade de demonstrar seu amor de maneira eficaz.

A estratégia do banco consiste em oferecer o serviço (plano de previdência) de forma amigável, explorando a preocupação e insegurança do adulto em relação ao futuro dos filhos. A representação infantil acionada (pura, inocente) mobiliza a afetividade e responsabilidade do adulto e procura convencer sobre a necessidade, nas palavras do anúncio, de demonstrar o amor de "uma maneira inteligente" (adquirindo o plano de previdência do banco), garantindo tranquilidade e segurança no futuro da criança.

\section{Itaú Bankfone: "Chegue em casa a tempo de pegar seu filho na infância”}

A leitura visual do anúncio do banco Itaú veiculado em 2003 (Figura 3), permite identificar, em primeiro plano, em destaque, um menino sorridente que encara o leitor e está com o dedo indicador apontado para o logotipo do Itaú Bankfone (letra “i” em formato de arroba, remetendo à tecnologia), como se estivesse colocando o pingo na 
letra "i".

A chamada publicitária enfatiza o serviço oferecido: "Itaú Bankfone. Feito para você fazer tudo". O texto verbal em destaque, em consonância com a fotografia, alerta: "Chegue em casa a tempo de pegar seu filho na infância". O banco oferece um serviço que promete facilitar e agilizar diversas transações bancárias, desafogando a rotina e fazendo o cliente ganhar tempo.

A representação de infância denota um apelo afetivo (pureza, inocência), mobilizando a culpa daqueles que também possuem filhos e julgam ser necessário dedicar mais tempo e atenção a eles. O serviço bankfonedestaca-se por ter sido anunciado de uma maneira diferente do que havia sido feito até então em relação a serviços do mesmo tipo: ao invés de retratar a tecnologia em si, o banco opta pela fotografia da criança em destaque, em um cenário à beira mar. $\mathrm{O}$ foco não está mais na materialização do serviço, mas, sim, na materialização das vantagens que pode proporcionar ao usuário. No caso do anúncio, mais tempo livre, que poderá ser direcionado para maior interação com os filhos.

Ao sublinhar verbalmente que a infância não dura para sempre e é um momento que precisa ser desfrutado agora para não trazer arrependimentos depois (quando o seu filho não estiver mais na infância), o enunciador faz com que o leitor se identifique com a organização e veja o serviço com simpatia. O texto verbal em destaque soa como um alerta aparentemente desprovido de segundas intenções (a infância não dura para sempre), criando para a organização um ethos quase altruísta, de alguém que pretende ajudar o leitor, fazendo tudo para ele ganhar tempo sem pedir nada em troca (já que as taxas e valores referentes ao serviço não são mencionados).

A estratégia adotada consiste em incitar a culpa do adulto (que vive hoje uma rotina cada vez mais atribulada), sublinhando a afirmação de que a infância um dia acaba. O banco surge para resolver o problema, ao oferecer um serviço que promete facilitar e agilizar diversas transações bancárias, desafogando a rotina e fazendo o cliente ganhar tempo.

\section{Imagens de infância e a contrução do ethos das organizações}

Pensando a publicidade de forma mais abrangente e em consonância com as ideias apresentadas até aqui, Rocha (2006) questiona a concepção de anúncio 
publicitário com a tarefa única e exclusiva de vender um produto, abrir mercado ou aumentar consumo, e propõe pensar o sistema publicitário como preocupado em disseminar estilos de vida, visões de mundo, sensações, emoções e até mesmo relações humanas. Seus significados são, portanto, compartilhados e coletivos. Por esse motivo, para o autor, a significação advinda desse tipo de material funciona como se fossem pistas para os modelos de existência, desejos e impasses de uma cultura, já que comunicam o que as pessoas têm em comum.

Vista como espaço de produção de significação, a publicidade pode ser compreendida também como o lugar onde são representados códigos culturais e onde significados são trocados, reforçados, construídos e redimensionados. Para Sabat (1999, p. 37), cada elemento que compõe um anúncio publicitário “é um signo que nos permite 'ler' a imagem de acordo com os códigos culturais que carregamos e/ou construir novos". Por consequência, o processo de significação envolvido nas imagens ou os signos produzidos pela sociedade não podem ser fixados definitivamente. Eles são marcas históricas, sociais e culturais que produzem e reproduzem representações.

Um primeiro olhar para os três anúncios analisados neste artigo já permite dizer que houve um refinamento das estratégias empregadas com o passar dos anos: inicialmente, como é possível verificar no anúncio-tipo do banco Real (1989, Figura 1), a criança dividia a cena com os adultos na fotografia, de forma a enfatizar a importância da relação familiar. A necessidade de garantir segurança e tranquilidade num tempo de desaceleração econômica parecia central nos anúncios da época. Em contrapartida, a partir dos anos 1990, a criança aparece muitas vezes sozinha na fotografia, como pode ser visto nos anúncios-tipo do banco Itaú de 1998 e 2003 (Figuras 2 e 3), num apelo a mais atenção e tempo do adulto, a fim de mobilizar a sua culpa por essa ausência, em consonância com a realidade vivenciada por muitas famílias atualmente.

Ao ponderar a respeito do que se destacou até aqui sobre a noção de infância nos anúncios das organizações bancárias, é possível sugerir que as organizações tornam-se uma poderosa fonte de significados, na medida em que o seu discurso tende a refletir os padrões socioculturais dos públicos. O sentimento de simpatia e pertencimento, que faz com que a sociedade se reconheça naquilo que é dito pela organização, é que permite a atualização dos padrões, valores e crenças colocados em circulação nos anúncios. Porém, o que se vê muitas vezes é o movimento de reprodução de padrões 
socioculturais de acordo com os interesses das organizações, que procuram restringir e direcionar os sentidos, convenientemente, de acordo com aquilo que podem oferecer aos públicos por meio de produtos e serviços. Assim, quando os bancos acionam uma representação de infância desprotegida, meiga e inocente para falar de si, como já exposto, o fazem para divulgar seguros de vida e planos de previdência, serviços que vêm ao encontro dos sentidos produzidos pelo anúncio: necessidade de proteger, cuidar e zelar pelo futuro das crianças. Da mesma forma, o acionamento da representação de infância que aparece sozinha apela para a finitude da infância e a falta de tempo recorrente no mundo adulto, oferecendo um serviço como o bankfone ou $\mathrm{o}$ homebanking, que prometem agilizar transações bancárias em nome do bem mais precioso da contemporaneidade: o tempo livre.

Nessa direção, observa-se que, embora o emprego de representações de infância pelas organizações tenha se ampliado significativamente na última década, o uso dessa eficiente fórmula para falar de si muitas vezes não recebe a devida atenção e tampouco é percebido em sua dimensão estratégica pela comunicação organizacional. A naturalidade com que se associa a noção de infância com os mais diversos perfis de organização faz passar despercebida a relação de poder capaz de instituir e afirmar uma imagem-conceito ${ }^{5}$ positiva, denotar legitimidade, garantir posicionamento de mercado e fortalecer o poder simbólico, ou, ainda, contribuir para a ampliação dos ganhos financeiros. De forma mais sutil, esse poder também é capaz de estabelecer fora do campo de visibilidade do público aspectos considerados menos relevantes da identidade organizacional ou com potência para despertar antipatia ou resistência.

De acordo com Bujes (2003), essa compreensão do poder nada tem a ver com a face negativa a que comumente é associado. A autora salienta a outra face dos efeitos do poder - que faz com que ele seja aceito, não por seus aspectos repressivos, mas pela sua potência, pela sua capacidade de produzir prazeres, saberes e discursos. Ao abandonar a hipótese repressiva associada ao poder e a sua noção negativa, é possível vê-lo se exercendo em todas as práticas, sustentando-se em verdades por meio de estratégias, mecanismos, táticas e arranjos sutis.

\footnotetext{
${ }^{5}$ De acordocomBaldissera, a imagem-conceito "é compreendida/explicada como umconstruto simbólico, complexo e sintetizante, de caráter judicativo/caracterizante e provisório, realizada pela alteridade (recepção) mediante permanentes tensões dialógicas, dialéticas e recursivas, intra e entre umadiversidade de elementos-força, tais como as informações e as percepções sobre a identidade (algo/alguém), a capacidade de compreensão, a cultura, o imaginário, a psique, a história e o contexto estruturado" (BALDISSERA, 2004, p. 278).
} 
No caso deste estudo, ao olhar mais atentamente para os anúncios analisados a fim de detectar os modos de funcionamento do poder, pode-se afirmar que a perspectiva naturalizada de significar a infância (re)afirmada pelos bancos ao longo dos anos vem ao encontro dos interesses das organizações em duas esferas: 1) construir e ofertar sentidos positivos de si; e 2) manter e (re)produzir sentidos ligados à representação de infância naturalizada, já que se servem desses significados na constituição do seu ethos.

Se o significado nada mais é do que uma invenção humana, instituída nas trocas e negociações de sentido, não se pode deixar de questionar a que interesses de poder estão articuladas as organizações e como estão comprometidas na invenção de determinados modos de ser criança. Compreender a comunicação organizacional como ordenadora e produtora de sentidos é tomá-la como prática social, assumindo a sua capacidade de influenciar na configuração da cultura, naturalizando e (re)afirmando modos de ser e estar no mundo. Mais do que isso, estar ciente do poder das organizações na constituição da sociedade prevê novas possibilidades, nuances e rupturas na compreensão dos sentidos produzidos por elas sobre si mesmas e sobre os fenômenos da cultura.

\section{Referências}

ANDRADE, Paula Deporte. A formação da infância do consumo - um estudo sobre crianças nos anúncios publicitários da revista Veja. 2011. 170 f. Dissertação (Mestrado em Educação) - Universidade Luterana do Brasil, Canoas, RS, 2011.

ARIÈS, Philippe. A criança e a vida familiar no antigo regime. Lisboa: Relógio D’Água, 1988.

BALDISSERA, Rudimar. Comunicação Organizacional na perspectiva da complexidade. Organicom (USP), São Paulo, v. 6, n. 10-11, p. 115-120, 2009. Disponível em: <http://www.revistas.usp.br/organicom/article/view/139013/134361>. Acesso em: 15 ago. 2012.

Imagem-conceito: anterior à comunicação, um lugar de significação. 2004. 295 f. Tese (Doutorado em Comunicação Social) - Pontifícia Universidade Católica do Rio Grande do Sul, Porto Alegre, 2004.

; SILVA, Magno Vieira da. Organizações comunicadas e ethos discursivo: imagens de si ofertadas em sites institucionais. In: CONGRESSO BRASILEIRO CIENTÍFICO DE COMUNICAÇÃO ORGANIZACIONAL E RELAÇÕES PÚBLICAS, 5.,2011, São Paulo. Anais... Disponível em: <http://www.abrapcorp.org.br/anais2011/trabalhos/trabalho_rudimar_magno.pdf>. Acesso em: 18 ago. 2012. 
BUCKINGHAM, David. Crescer na era das mídias eletrônicas. São Paulo: Loyola, 2007.

BUJES, Maria Isabel Edelweiss. Alguns apontamentos sobre as relações infância/poder numa perspectiva foucaultiana.In: REUNIÃO ANUAL DA ASSOCIAÇÃO NACIONAL DE PÓS-GRADUAÇÃO E PESQUISA EM EDUCAÇÃO, 26., 2003, Poços de Caldas (MG). Disponível em:

<26reuniao.anped.org.br/outrostextos/mc07mariaisabelbujes.doc >. Acesso em: 02 abr. 2012.

Artes de governar a infância: linguagem e naturalização da criança na abordagem de educação infantil da Reggio Emília.Educação em Revista [online], Belo Horizonte, n. 48, dez. 2008, p. 101-123. Disponível em: <http://www.scielo.br/pdf/edur/n48/a06n48.pdf>. Acesso em: 02 abr. 2012.

FAUSTO, Boris. História concisa do Brasil. São Paulo: Edusp, 2011.

FOUCAULT, Michel. Vigiar e punir.Petrópolis: Vozes, 1999.

HALL, Stuart. The work of representation. In: (Ed.). Representation.

Cultural representation and cultural signifying practices. London; Thousand Oaks; New Delhi: Sage; Open University, 1997.

KOHAN, Walter O. Infância. Entre educação e filosofia. Belo Horizonte: Autêntica, 2003.

MAINGUENEAU, Dominique. A propósito do ethos. In: MOTTA, Ana Raquel; SALGADO, Luciana (Org.). Ethos discursivo. São Paulo: Contexto, 2008a.

. Cenas da enunciação. São Paulo: Parábola Editorial, 2008b.

POSTMAN, Neil. O desaparecimento da infância. Rio de Janeiro: Graphia, 1999.

ROCHA, Everardo. Representações do consumo: estudos sobre a narrativa publicitária. Rio de Janeiro: PUC-Rio; Mauad, 2006.

SABAT, Ruth. Entre signos e imagens: gênero e sexualidade na pedagogia da mídia. 1999. 136f. Dissertação (Programa de Pós-Graduação em Educação) - Faculdade de Educação, Universidade Federal do Rio Grande do Sul, Porto Alegre, 1999.

VERÓN, Eliseo. A produção de sentido. São Paulo: Cultrix, 1980.

Fragmentos de um tecido. São Leopoldo, RS: Editora Unisinos, 2004.

Submetidoem: 14.03 .2016

Aprovadoem: 28.06.2018 